\title{
Neglectful Parenting: A Child Overdosed with Phenergan Syrup
}

\author{
Anila Sarwar, Ayesha Jabeen
}

\begin{abstract}
Misuse of Over the Counter (OTC) medication is a common issue however, the long term consequences of this unchecked act are less stressed particularly in child care. The current case is of an eight years old boy studying in a Special Education School; referred for the Clinical assessment and intervention of academic and behavioral problems. The adaptive behavior assessment revealed that the child had moderate form of intellectual disability. It was found in anecdotal records that child had consumed heavy quantity of syrup Phenergan in his infant years. The focus of brief therapeutic intervention was to enhance his current adaptive behavior functioning. Multiple stakeholders including parents, physician pharmacist should drift their attention towards this very issue.
\end{abstract}

KEY WORDS: Parenting, Phenergan syrup, Intellectual disability, PGEE

This article may be cited as: Sarwar A, Jabeen A. Neglectful Parenting: A Child Overdosed with Phenergan Syrup. J Liaquat Uni Med Health Sci. 2018;17(03):195-7. doi: $10.22442 /$ jlumhs.181730577

\section{INTRODUCTION}

One of the renowned drug of a group is famous with the name of "Phenergan" which is discouraged to be used for children according to American Academy of Pediatrics ${ }^{1}$ because this drug fosters high procedural sedation in the children and effects functions of central nervous system. Excessive use of certain group of drugs (e.g promethazine.) plays direct or indirect roles for the likelihood of Intellectual disability (ID) in children. Overdose and unchecked use of promethazine group of drugs including Phenergan affects the central nervous system activity along with neuroleptic malignant syndrome ${ }^{2}$. Other core effects of its overdose include CNS anticholinergic effects which increase the likelihood for the development of cognitive and memory impairment (core symptoms of ID) ${ }^{3}$. The consequences of these syndromes and other side effects hinders the person to function normally that's why children exhibit poor adaptive skills. ID is one of the developmental disorders which disrupt the pathways of intellectual and adaptive functioning of a person especially in practical, social and conceptual domains ${ }^{4}$. Due to its prevailing prevalence which is approximately 10.37 over 1000, it becomes very essential to know about its etiological factors ${ }^{5}$. Studies suggested there are much genetic and non genetic vulnerabilities for intellectual disability like prenatal factors like advanced maternal age, maternal' tobacco or alcohol abuse, diabetes, and hypertension; others factors like low birth weight or preterm birth ${ }^{2}$.

The role of parents or primary caregivers is considered very important in the training and development of children with ID because children have most contact with these figures. Although there are less reported number of incidences of misuse of drugs by parents but they do exist. The aim of the current case study was to highlight the importance of such etiological factors of ID where the psychology of a nurturing figure can disrupts the biopsychology of the other.

\section{CASE REPORT}

The patient of the current case study was an 8 years old boy. He was studying in a special education school and referred by his school teacher with different academics and behavioral issues. Ethical considerations were followed before intimating psychotherapeutic process which involved anonymity and informed consent from family (father). Interviews with father and teacher revealed that he belonged to a middle socio-economic status family and the patient's mother was reported to be suffering from several psychological issues like, being depressed, aggressive, punitive and unconcerned for her children. Due to this reason the patient suffered maltreatment in his early childhood.

The patient was a healthy child at the time of his birth. He was reported to have age appropriate milestones (e.g. sitting, crawling, and walking) until he fell down in a pot of hot water and got burnt on left side of his body at the age of two. He was taken to hospital and prescribed many medicines along with syrup phenergan. Some way the mother of patient came to know that phenergan is a very solid agent to increase the sleep hours of the children. So she persistently used this syrup since the patient got a severe attack of abnormal patterns of body movement and self injurious behavior like biting, hitting etc at the age of four years. His father accidently found 24 bottles of 
Phenergan syrup; some filled others half from a kitchen cabinet. The emergency treatment saved the patient but this event caused his parents to divorce. The patient was over the barrel of her elder sister, who at the age of 14 was managing home and her siblings as well studying. The busy routine of everyone at home and syrup's side effect cause the patient to gradually lose his speech and get indulge in more aggressive patterns.

These two major problems didn't let him to study at a normal school and he got admission in a special school of education at the age of seven. There, the patient was assessed through different adaptive behavior modalities and the results revealed 6-7 years of discrepancy between functional and chronological age of the patient (Table I). The key summarization of the assessment revealed severe linguistic damage (expressive) and cognitive deficient along with poor social skills; and the patient suspected to be with the problem of ID (Moderate).

\section{TABLE I: AREAS, FUNCTIONAL LEVEL AND DISCREPANCY OF PATIENT BETWEEN FUNCTIONAL AND CHRONOLOGICAL AGE ON PORTAGE GUIDE TO EARLY EDUCATION}

\begin{tabular}{|l|c|c|}
\hline Area of PGEE & $\begin{array}{c}\text { Current Functional } \\
\text { level of patient (years) }\end{array}$ & $\begin{array}{c}\text { Discrepancy } \\
\text { (years) }\end{array}$ \\
\hline Self help & $4-5$ & $3-4$ \\
\hline Motor & $3-4$ & $4-5$ \\
\hline Socialization & $3-4$ & $4-5$ \\
\hline Cognitive & $1-2$ & $6-7$ \\
\hline Language & $1-2$ & $6-7$ \\
\hline
\end{tabular}

The outcome was satisfactory as the patient was able to perform many of the tasks at his own.

\section{DISCUSSION}

In the current case, those neglected factors which are responsible for delayed adaptive functioning in children were discussed. The whole therapeutic process consisted of 15 numbers of sessions in which assessment modalities of single case study design gave an in depth details of discrepancy between the chronological and functional level of the patient. It also highlighted the reasons behind the excessive and deficient behavior patterns. This case study brought the importance of parental rearing behaviors in front that parental role for casting ID is nonnegotiable ${ }^{6}$. Children are like sponges, they deeply absorb whatever they sense around and are highly sensitive for the way their parents treat them. The mal treatment of parents disturb the biopsychosocial functioning of their children and make children vulnerable $^{7}$ as seen in the current case. Although neurobiology of the patient gave the justification for developing ID but it went all settled by the mal rearing maternal behavior. The intervention plan aimed to promote the self help skills of the patient, decreasing intensity and frequency of aggressive behaviors, teaching his name and primary color recognition, which ended with effective results. The role of father and teacher were very significant for increasing the effectiveness of intervention as they showed compliance towards the psycho-education strategies.

Apart from this pre and post ratings of three major problems (speech, writing and hitting others) by the referral person was taken which validated the success of interventional strategies, it's as following:

The following figure showed the pre and post intervention results of the patient.

\section{FIGURE:}

\section{PRE AND POST ASSESSMENT OF GOALS}

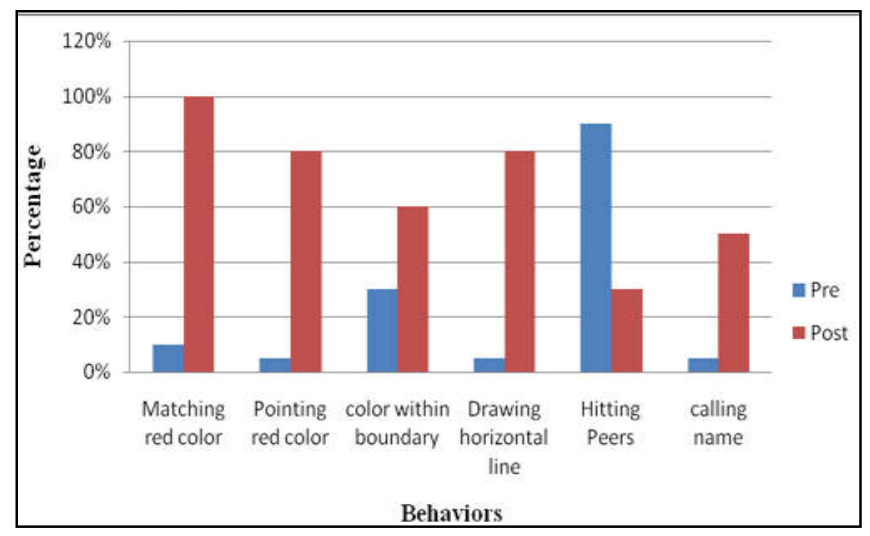

TABLE II: PROBLEMATIC BEHAVIORS, PRE AND POST INTERVENTION RATINGS FORM THE REFERRAL PERSON

\begin{tabular}{|l|c|c|}
\hline \multicolumn{1}{|c|}{ Problem } & $\begin{array}{c}\text { Pre-intervention } \\
\text { rating }\end{array}$ & $\begin{array}{c}\text { Post-intervention } \\
\text { rating }\end{array}$ \\
\hline $\begin{array}{l}\text { Speaking name } \\
\text { properly }\end{array}$ & 9 & 6 \\
\hline Color recognition & 10 & 5 \\
\hline $\begin{array}{l}\text { Aggressive } \\
\text { Behavior }\end{array}$ & 9 & 3 \\
\hline
\end{tabular}

Note. $10=$ most problematic, $0=$ least problematic

\section{CONCLUSION}

The biopsychosocial factors included in the current case study gives a holistic approach in understanding complexities involved in diagnosis of ID. Overall this case study was an extensive piece of literature for 
etiology of ID, parental roles, and misuse of OTC. It also holds limitation of less generalizability to a broader population of ID.

\section{REFERENCES}

1. American Psychiatric Association. Diagnostic and Statistical Manual of Mental Disorders. 2013; 5: 33.

2. Buck M. Promethazine: Recommendations for safe use in children. Pediatric Pharmacotherapy 2010; 16 (3). Available from: https:// med.virginia.edu/pediatrics/wp-content/uploads/ sites/237/2015/12/201003.pdf.

3. Walsh GM (2011). Antihistamines (H1 receptor antagonists) In: Aronson JK, editor. Side Effects of Drugs Annual: A worldwide yearly survey of new data in adverse drug reactions (Vol 33, pp. 345-351). Elsevier Science.

4. Maulik PK, Mascarenhas MN, Mathers CD, Dua T, Saxena S. Prevalence of intellectual disability: A meta-analysis of population-based studies. Res Dev Disabil 2011; 32: 419-36. Doi: 10.1016/ j.ridd.2010.12.018

5. Huang J, Zhu T, Qu Y, Mu D. Prenatal, Perinatal and Neonatal Risk Factors for Intellectual Disability: A Systemic Review and MetaAnalysis. PLOS ONE 2016; 11(4): e0153655. Doi:10.1371/journal.pone.0153655

6. Warren SF, Brady NC. The role of maternal responsivity in the development of children with intellectual disabilities. Mental retardation and developmental disabilities research reviews. 2007; 13(4): 330-38. Doi: https://doi.org/10.1002/ mrdd.20177

7. Winston R, Chicot R. The importance of early bonding on the long-term mental health and resilience of children. London J Prim Care 2016; 8(1): 12-14. doi: 10.1080/17571472.2015. 1133012

8. Yanai K. Anticholinergic activity of antihistamines. Clin Neurophysiol 2012;123(4):633-4. doi: 10.1016/j.clinph.2011.09.005.

AUTHOR AFFILIATION:
Anila Sarwar (Corresponding Author)
Research Associate
University of Management and Technology
Lahore, Punjab-Pakistan.
Email: anila.sarwar@umt.edu.pk
Ayesha Jabeen
Assistant Professor
Institute of Clinical Psychology
University of Management and Technology
Lahore, Punjab-Pakistan.

